\title{
Apenas brincando? Brinquedos e brincadeiras na educação infantil: o que dizem as educadoras?
}

\author{
Just playing? Toys and games in childhood education: what the \\ educators say?
}

Marta Regina Paulo da Silva Doutora em Educação pela UNICAMP Docente-Pesquisadora do PPGE da Universidade Municipal de São Caetano do Sul. São Caetano do Sul, São Paulo - Brasil martarps@uol.com.br

Luciene Franceschini Mestre em Educação pela Universidade Municipal de São Caetano do Sul Professora da Rede Municipal de Educação de São Caetano do Sul franceschini.luciene@gmail.com

Resumo: Este artigo compartilha resultados de uma pesquisa de mestrado, que objetivou compreender como o brincar está inserido na educação infantil de um município do Grande ABC Paulista, visando contribuir com a construção de práticas pedagógicas mais brincantes. A opção metodológica foi por uma pesquisa qualitativa, por meio de análise documental, estudo exploratório e grupos focais com professoras e formadoras. O trabalho dialogou com estudos da pedagogia e da sociologia da infância. A análise dos dados revelou poucos momentos do cotidiano destinados ao brincar, sendo tal fato justificado em função de uma organização que privilegia atividades voltadas à alfabetização e à matemática, demarcando um modelo escolarizado, que termina por marginalizar a iniciativa, a expressão e a criatividade de meninos e meninas. A pesquisa indicou a necessidade de uma formação docente dialógica, sendo esta uma reivindicação das professoras, de modo a construir práticas pedagógicas brincantes que primem pelas descobertas, criatividade e maravilhamento.

Palavras-chave: Brincar. Educação Infantil. Práticas pedagógicas brincantes.

Abstract: The article shares results of a master's research, which aimed to understand how play is inserted into early childhood education of a municipality in the Grande ABC Paulista from the perspective of contributing to the construction of more playful pedagogical practices. The methodological option was a qualitative research that had as its procedures: documentary analysis, exploratory study and focus groups organized with teachers and teacher trainers. The work had a dialogue with the studies of childhood pedagogy and sociology. The analysis of the data revealed few daily moments reserved for play, this fact being justified by an organization that values activities focused on literacy and mathematics, building a school model that ends up marginalizing the initiative, expression and creativity of boys and girls. The research indicated the need of a dialogical teacher training, as a teachers' requirement, in order to construct pedagogical practices that excel by the discoveries, creativity and wonder.

Keywords: Play. Childhood education. Playful pedagogical practices. 


\section{Introdução}

A educação de crianças pequenas foi caracterizada, durante um grande período da história, como sendo de pouca importância e restringia-se, no caso de creches, aos cuidados com higiene e alimentação. Nota-se que, após a promulgação da Constituição de 1988 (BRASIL, 1988) e da Lei de Diretrizes e Bases no 9.394/96 (BRASIL, 1996), foi dada maior relevância à educação infantil e à criança, que começou a ser reconhecida como um sujeito de direitos, surgindo nesse contexto, preocupações com o seu desenvolvimento, tanto em relação aos aspectos físicos como psicológicos, cognitivos e sociais. No bojo dessas mudanças, as interações sociais e as brincadeiras passaram a ser consideradas como eixos estruturantes para uma educação de qualidade, conforme definido nas Diretrizes Curriculares Nacionais para a Educação Infantil - DCNEI (BRASIL, 2010).

Diversos(as) autores(as), dentre eles(as), Brougère (2008), Corsaro (2011) e Prado (1998), compreendem o brincar como elemento essencial na formação do sujeito enquanto ser social. De acordo com tais autores(as), a brincadeira constitui um fenômeno social e é aprendida no convívio com o(a) outro(a). Compreender sobre a ludicidade e o brincar no espaço educativo é fundamental, uma vez que as crianças também produzem cultura enquanto brincam. Entretanto, como denuncia Kishimoto (2014), na educação infantil a brincadeira nem sempre é considerada, sendo o modelo escolar hegemônico ainda muito presente em algumas instituições.

Tal modelo é fruto de uma sociedade adultocêntrica, em que o brincar é substituído, muitas vezes, por práticas grafocêntricas. Espera-se que as crianças se insiram cada vez mais cedo no sistema de produção capitalista, de modo que nas instituições de educação infantil lhes sejam designadas atividades que busquem acelerar o processo de aquisição da escrita e da leitura, em detrimento das brincadeiras e de outras formas de expressão. Com isso, não se coloca que a criança pequena não deva ter acesso ao mundo da cultura escrita, pois este é um direito que ela tem. O que se aponta é a supremacia de uma linguagem sobre as outras. Nas palavras poéticas do educador italiano Loris Malaguzzi (1999), das cem linguagens a escola lhe rouba noventa e nove.

Frente a este cenário, cabe questionar: de que forma os brinquedos e as brincadeiras estão inseridos no cotidiano da educação infantil? No intuito de responder a esta inquietação, a pesquisa que aqui se apresenta teve como objetivo central: compreender como os brinquedos e as brincadeiras estão inseridos nas instituições municipais de educação infantil de um município da região do Grande ABC Paulista, na perspectiva de contribuir com a construção de práticas pedagógicas mais brincantes. 


\section{O brincar e as culturas infantis}

A brincadeira é a atividade central na vida das crianças, sendo uma das maneiras pelas quais elas leem e dizem o mundo. É algo sério, e embora seja impossível de ser enquadrada em uma única definição, há algumas características que a tipificam, tal como aborda Brougère (1998, p. 3): “[...] um meio de comunicação, de prazer e de recreação. O que talvez, caracterize a brincadeira, em geral, é ser também um espaço, uma possibilidade de ação que a criança domine ou, pelo menos, exerça em função de sua própria iniciativa”. Desse modo, as brincadeiras constituem-se como momentos de imprevisibilidade, de negociações, nos quais as crianças tomam decisões. Por meio do brincar, elas aprendem.

Como meio de comunicação, para que se brinque, é necessário que exista uma manifestação entre as crianças, verbal ou não verbal, de que aquela situação se trata de uma brincadeira. E, apesar de toda brincadeira pressupor regras, para brincar deve existir um acordo sobre estas, as quais podem ser modificadas ou criadas conforme o desejo de quem brinca.

Mesmo sendo um espaço rico no que tange às aprendizagens, evidencia-se que, muitas vezes, as brincadeiras são utilizadas como práticas disciplinadoras, como, por exemplo, para organizar filas nos diferentes momentos da rotina, de modo a controlar as crianças e manter o silêncio. Percebe-se que a brincadeira cumpre, nestes casos, a função de ser um recurso pedagógico para disciplinar os corpos de meninos(as). Outro uso das brincadeiras refere-se às práticas escolarizantes. No que diz respeito à educação infantil, Wajskop (2012, p. 29) afirma que:

Ao fazer isso, ao mesmo tempo em que bloqueia a organização independente das crianças para a brincadeira, essas práticas pré-escolares, através do trabalho lúdico didatizado, infantilizam os alunos, como se sua ação simbólica servisse apenas para exercitar e facilitar (para o professor), a transmissão de determinada visão do mundo, definida a priori pela escola.

Para Kishimoto (s/d), as propostas de educação infantil dividem-se entre aquelas que reproduzem o ensino fundamental, cuja ênfase se encontra na alfabetização e no ensino de números, em um processo de escolarização, e aquelas que introduzem o brincar valorizando a socialização e as experiências das crianças.

Em relação a esta segunda proposta, Brougère (2008), Corsaro (2011), Kishimoto (2011; 2015), Prado (1998) e Wajskop (1995; 2012) apontam a importância do brincar, principalmente do brincar livre, das escolhas das crianças pelo brincar e por quanto tempo a brincadeira durar. Esses(as) autores(as) ressaltam que, por meio das brincadeiras, é 
possível compreender e recriar as experiências socioculturais do mundo adulto. O brincar possibilita às crianças serem elas mesmas ou quem quiserem ser, propiciando experimentarem, imaginarem e criarem e, assim, não se restringe a um artifício pedagógico para doutrinar e disciplinar meninos(as).

Os(as) professores(as), ao organizarem os contextos das brincadeiras, precisam considerar que estas são caracterizadas pela liberdade, de modo a propiciarem momentos que possibilitem variadas experimentações e criações. Além dos espaços designados ao brincar, também se faz necessário observar a forma como os brinquedos ou objetos que estimulam o brincar são disponibilizados. Brougère (2008) especifica que, quando os brinquedos assumem sentido lúdico, funcionam como suporte para as brincadeiras e, caso isso não aconteça, eles são apenas objetos.

Por meio do brincar, as crianças se movimentam, investigam e conhecem o mundo à sua volta. Um mundo físico, repleto de objetos e materiais que manipulam e experimentam. Um mundo social, que proporciona referências das práticas culturais organizadas por cada grupo humano. Quando brincam, elas não apenas reproduzem a cultura adulta, mas em um processo criativo produzem as culturas infantis (BROUGÈRE, 2008; CORSARO, 2011; PRADO, 1998; SILVA, 2017a).

Neste trabalho, a definição de cultura reconhece a pluralização das sociedades. Desse modo, a concepção assumida se opõe a de uma cultura dominante e única. Segundo Barbosa (2014), a partir de meados do século XX, novas concepções de cultura emergiram e, com elas, o reconhecimento da possibilidade de todos(as), inclusive as crianças, serem produtores(as) de cultura. Assim, meninos e meninas produzem cultura a partir dos contextos em que estão inseridos(as), sendo que as brincadeiras constituem momentos privilegiados para essa produção.

De acordo com Corsaro (2011), as crianças não são agentes passivas da cultura. Elas assumem posturas ativas na apropriação das rotinas culturais, realizando reinterpretações, sendo capazes de produzirem cultura a partir daquilo que os(as) adultos(as) lhes disponibilizam, ou seja, apropriam-se da cultura e podem modificá-la. O autor denominou esse processo como reprodução interpretativa. Dessa maneira, as crianças não se restringem a imitar o mundo adulto, mas, coletivamente, apropriam-se com criatividade e atribuem sentido.

Nesta perspectiva, o direito ao brincar precisa ser garantido. Para Marcellino (2003), faz-se necessário que as instituições de educação infantil resgatem a produção de cultura por parte das crianças e reflitam sobre o tempo disponibilizado para as obrigações escolares 
e para os momentos de brincadeiras. Ressalta-se que o direito a brincadeira é garantido por leis, tais como no artigo 227 da Constituição Federal (BRASIL, 1988), no artigo 16, inciso IV, do Estatuto da Criança e do Adolescente - ECA (BRASIL, 1990) e na Lei de Diretrizes Bases da Educação Nacional, Lei no 9.394/96 (BRASIL, 1996). Entretanto, cabe indagar se este tem seu papel garantido nas instituições de educação infantil.

A proposta curricular do município onde se deu esta investigação apresenta a brincadeira como uma atividade social e cultural, orientando as instituições a planejarem tempo, espaço e materiais para as brincadeiras de forma a considerar as diversas demandas infantis e seus cotidianos. Este dispositivo legal reconhece, ainda, a criança como produtora de cultura, defendendo seus direitos e necessidades ao priorizar, no currículo, o ato de brincar. Contudo, como tal direito se materializa no cotidiano de creches e préescolas deste município?

\section{O percurso metodológico}

Ao problematizar como ocorre o brincar nas creches e pré-escolas municipais, foram delimitados procedimentos metodológicos que visassem compreender a realidade investigada. Assim, foi realizada a análise da proposta curricular do município, um estudo exploratório e, posteriormente, foram formados grupos focais com professoras e formadoras de educação infantil.

O estudo exploratório teve como finalidade afinar os objetivos e contribuir para a elaboração de um roteiro para o desenvolvimento dos grupos focais e ocorreu a partir de observações diretas da prática de cinco professoras de uma pré-escola durante uma semana. Nas cinco turmas observadas com crianças de quatro e cinco anos, as professoras referiram-se à falta de materiais adequados ao brincar, ao espaço inadequado, à falta de cursos de formação durante o expediente e à cobrança intensa, por parte da gestão, com relação à necessidade de atrelar o brincar às práticas de escolarização. Tais práticas se fizeram presentes em vários momentos como, por exemplo, boliche associado ao conhecimento dos números e das quantidades, campeonatos para selecionar e reconhecer letras e muitos outros jogos direcionados à alfabetização, sobretudo nas turmas de cinco anos. Observou-se também, em determinadas turmas, que nas brincadeiras as crianças tinham que permanecer sentadas e em silêncio, sendo os lugares escolhidos pela própria docente. Questões de gênero foram evidenciadas quando alguns meninos vestiam fantasias de princesas, o que era questionado pelas professoras. 
Tal cenário levou a indagar as concepções que permeiam a prática pedagógica desta instituição. Afinal, como professoras e gestoras compreendem a educação de crianças pequenas? Para elas, quem são as crianças? E o brincar, qual o seu sentido?

Tomando por base estas observações, em diálogo com o referencial teórico da presente pesquisa, tornou-se possível um melhor delineamento do caminho metodológico percorrido nos grupos focais. A opção pelo grupo focal ocorreu por ser essa uma técnica importante para “o conhecimento das representações, percepções, crenças, hábitos, valores, restrições, preconceitos, linguagens e simbologias prevalentes no trato de uma dada questão por pessoas que partilham alguns traços em comum, relevantes para o estudo do problema visado" (GATTI, 2012, p. 11).

Nesse sentido, os grupos focais contribuíram para a compreensão das diferentes perspectivas sobre o brincar, envolvendo as práticas cotidianas, atitudes e comportamentos relevantes para esta pesquisa. Cabe pontuar que tal técnica é utilizada quando se visa compreender tanto diferenças e divergências, como contraposições e contradições (GAT'TI, 2012), visto que, a contradição pode contribuir com a apreensão do real.

$\mathrm{Na}$ presente pesquisa, foram realizados dois grupos focais: um com cinco professoras formadoras (aqui tratadas com F1, F2, F3, F4 e F5) e, o outro, com cinco professoras de educação infantil (P1, P2, P3, P4 e P5). Cada grupo teve duração de, aproximadamente, duas horas e trinta minutos. A forma de registro dos grupos focais foi por meio de gravações em áudio e também registros escritos pela própria pesquisadora e por uma assistente.

Ressalta-se que, após as observações realizadas no estudo exploratório, foi possível elaborar as seguintes categorias para os grupos focais, que foram desenvolvidas em formato de palavras-chave e de questionamentos: Brincar na educação infantil; Papel dos(as) professores(as) no brincar; Tempo, espaço e materiais para brincadeiras; Brincadeiras e conteúdos escolares; O brincar e as culturas infantis.

As gravações em áudio foram transcritas e categorizadas nas respectivas categorias, bem como os registros escritos, que possibilitaram as análises qualitativas dos conteúdos recorrentes, relevantes, críticos e discordantes (GATTI, 2012). Para a análise dos dados, a opção foi pela análise de conteúdo de Bardin (2002), que visa explicar e sistematizar os conteúdos das mensagens emitidas e o significado de tais conteúdos. Também se utilizou da pesquisa de Franco (2008), a fim de auxiliar no momento das interpretações dos dados. 
A análise de conteúdo possibilitou compreender os dados coletados, uma vez que permitiu extrair dos discursos presentes das docentes e das formadoras seus conteúdos manifestos e latentes, produzindo sentidos.

\section{Brinquedos e brincadeiras: as vozes das professoras e das formadoras}

A partir da análise dos dados, foi possível verificar que as professoras e as formadoras consideram o brincar na educação infantil como um elemento importante e necessário. Porém, segundo as docentes, em decorrência da necessidade de cumprir uma rotina determinada, o tempo destinado às brincadeiras livres torna-se limitado ao parque ou quando são proporcionadas as oficinas de convívio, sendo estas, momentos nos quais as crianças têm a liberdade de escolher os espaços e com quem brincar. Assim, relataram que algumas vezes precisam burlar tal rotina para que possam proporcionar às crianças que brinquem livremente, como se verifica no depoimento abaixo:

Teve um ano que eu tive um G2 (turma com crianças de 2 anos de idade) em meio período, e não tinha na rotina de um G2 o espaço para brincadeira livre. $\mathrm{O}$ que eu fiz? Burlei o sistema. Fiz uma sequência didática de linguagem através das brincadeiras simbólicas para justificar o tempo que eu estava brincando com as crianças. (P2)

As formadoras pontuaram existir estes tempos para o brincar, mas que, por vezes, são mal planejados dentro da instituição. Uma das formadoras (F3) reconheceu a necessidade de rever esta organização do cotidiano das instituições, ao afirmar que tem ciência de que os(as) professores(as) sentem-se pressionados(as) para o cumprimento da rotina.

Ainda com relação ao tempo para o brincar, observa-se diferenças em função da faixa etária, sendo uma duração maior para as crianças de um até dois anos, e menor para aquelas de três, quatro e cinco anos. Segundo as professoras, com as crianças maiores há a necessidade de realização de muitas atividades que envolvem práticas de alfabetização. Essas falas das docentes vão ao encontro do que se observou no estudo exploratório, em que foi possível constatar que a maioria das brincadeiras estava atrelada às áreas de conhecimento. P1 ressaltou que muita gente considera que ser professor(a) é passar lição, conteúdos de alfabetização e, assim, acabam por banalizar o brincar, o que denota o quanto ainda prevalece no imaginário social um modelo hegemônico de escola, como denunciado por Kishimoto (2014).

Contudo, somos seres simbólicos, criamos muitos códigos para nos expressar, pois várias são as nossas linguagens. Reconhecer e valorizar essas múltiplas linguagens é um dos 
desafios da educação da pequena infância, o que significa desmistificar a leitura e a escrita como objeto central da escolarização das crianças, como propõe Barbosa (2007), e preocuparmo-nos com todas as formas de leitura e escrita, ou seja, com todas as linguagens que, como humanos, fomos construindo ao longo da história: o desenho, a pintura, a dança, a música, a brincadeira, dentre outras.

De acordo com as DCNEI (BRASIL, 2010), os(as) professores(as) durante as brincadeiras, devem levar em conta as suas interações com as crianças e destas entre elas. Segundo este documento, o brincar é fundamental para o conhecimento do mundo social, para produção, conservação e recriação do repertório lúdico. Tanto as professoras como as formadoras abordaram estes aspectos, quando mencionaram que é importante permitir que as crianças se expressem e estejam livres para escolher com quem brincar. Contudo, algumas falas das docentes sugerem certa ideia de controle, quando, por exemplo, P2 afirmou que é preciso que o(a) professor(a) antecipe os riscos que a brincadeira pode acarretar; P4 também declarou que, ao mesmo tempo em que acredita que os(as) professores(as) precisam deixar as crianças livres para descobrirem coisas, não é possível deixar elas subirem em qualquer lugar; P5 fez referência ao fato de que existem crianças "teimosas" que não respeitam os combinados. Tais depoimentos trazem à tona o limite tênue entre segurança e controle, entre atenção e controle, o que faz pensar que, nesse binômio atenção/controle, como discute Faria (1999, p. 72), é preciso “[...] garantir que a balança penda para a 'atenção' e o 'controle' deverá estar voltado, não para o individualismo, o conformismo e a submissão, mas para o verdadeiro aprendizado de vida em sociedade: solidariedade, generosidade, cooperação, amizade".

A formadora F3 destacou o papel dos(as) professores(as) no planejamento das brincadeiras, que deve respeitar os diferentes ritmos das crianças e sua diversidade de interesses. Tal planejamento implica em um olhar atento e uma escuta sensível para as crianças, em que “[...] os professores seguem as crianças, não seguem planos" como nos provoca Malaguzzi (1999, p. 100). Isso não significa que não haja um planejamento intencional das atividades, mas este "[...] pode e deve ser modificado ao longo de todo o processo em função dos interesses e necessidades das crianças, sendo, portanto, suficientemente flexível para, partindo das crianças, continuar com elas, acompanhando seus itinerários individuais e coletivos" (SILVA, 2017b, p. 87). Também aparecem nas falas das formadoras a observação e o registro como papéis dos(as) docentes no brincar. De acordo com Kishimoto (2010) e Wajskop (1995), os instrumentos de observação e registro são importantes e servem como parâmetro para o planejamento das brincadeiras. 
O papel do(a) educador(a) perpassa a própria concepção que este(a) possui acerca do brincar. Nota-se, a partir dos dados, que as professoras e as formadoras apresentam concepções diversas sobre o brincar: algumas o compreendem como algo nato, outras, como uma construção social e cultural. A compreensão do brincar como algo nato remete a certa compreensão inatista do desenvolvimento humano, em que as características ou capacidades básicas das pessoas, tais como comportamento, personalidade, entre outras, já estariam praticamente determinadas a partir do momento do nascimento, ou seja, não seriam aprendidas.

Com relação à compreensão do brincar como construção social, professoras e formadoras apontaram que este é algo que é aprendido na relação com o(a) outro(a), o que vai ao encontro das proposições de pesquisadores(as) como Brougère (2008), Corsaro (2011) e Kishimoto (2015), que afirmam que as brincadeiras não evoluem naturalmente, ou seja, não são naturais e espontâneas nas crianças, mas sim um fenômeno de construção social que é aprendido e que se caracteriza também como um ato de escolha das próprias crianças. Isso parece se confirmar quando se verifica que a maioria das professoras reconhece o brincar como um espaço de descoberta do mundo. P1 menciona, inclusive, a uma atitude investigativa das crianças, ao se referir ao brincar como uma "maneira de pesquisa". É interessante observar que a dimensão do prazer, do divertimento e da liberdade só aparece nos relatos de duas formadoras (F4 e F5), não estando presentes entre as professoras. O brincar como transgressão e resistência não aparecem nas falas das professoras e formadoras.

Todas as professoras e formadoras, entretanto, concordaram acerca de que as interações são fundamentais nas brincadeiras, como se verifica no depoimento de P4:

[...] às vezes a gente programa uma coisa pra fazer [...] só que as crianças, se você permitir, elas sempre vão além do que você planejou e cabe a gente que está ali com o olhar saber dar margem para aquilo. Então, a gente precisa dar corda para as crianças continuarem brincando porque assim elas vão aprender coisas novas uns com os outros. [...] é uma riqueza brincar. (P4)

De acordo com Brougère (1998), a brincadeira só é possível se houver espaço para decisão da criança, e é por meio do brincar que as interações e aprendizagens sociais emergem. Verifica-se uma preocupação para que isso aconteça tanto nas falas das professoras como das formadoras. P4 destacou que, se for permitido que as crianças brinquem e não se limitem ao que foi anteriormente planejado, há a possibilidade de aprenderem mais por intermédio das interações com outras crianças, fator que reafirma os estudos de Corsaro (2011), Brougère (2008), Silva (2017a; 2017b) e Prado (1998), quando 
evidenciam que, por meio das relações sociais estabelecidas, as crianças estabelecem novas criações e podem transformá-las, construindo cultura.

Professoras e formadoras concordam que há diferenças em como cada equipe gestora e de professores(as) considera o brincar. Nas observações do estudo exploratório, notou-se que, nos momentos de brincadeiras no parque, as professoras levaram cadeiras e sentaram para observar as crianças, interagindo com elas apenas em momentos destinados ao que o grupo compreende como segurança. Sobre a própria interação com as crianças durante as brincadeiras, as docentes alegaram não ter tempo, uma vez que necessitam cumprir as rotinas administrativas e burocráticas, como: relatórios, fichas e demais procedimentos.

Diferenças também foram observadas no modo como cada instituição organiza a aquisição e a distribuição dos materiais para as brincadeiras. Em algumas, a gestão decide com a equipe docente, já em outras, isso não acontece. As professoras, tanto no grupo focal quanto no estudo exploratório, apontaram para a falta de materiais para o brincar, fato sobre o qual as formadoras discordam alegando que há brinquedos e também espaços para as brincadeiras.

P1 explicou que mudou o seu jeito de realizar o brincar e que, atualmente, cria o espaço favorecendo a liberdade para que as crianças investiguem os materiais e explorem o que foi proposto. Além disso, a professora comentou que aprende juntamente com as crianças, o que é consonante ao que orientam as DCNEI (BRASIL, 2010), ou seja, que a interação com os brinquedos e com os materiais é primordial para o conhecimento do mundo. Com relação aos materiais não estruturados, as professoras apontaram que, em algumas escolas, a direção os visualiza como "lixo". Para P5, há diretoras que compreendem a importância do uso de tais materiais, mas há também aquelas que acreditam não terem qualquer serventia e que, portanto, precisam ser descartados. F1 também relatou que há escolas que consideram estes materiais como descartáveis.

Ainda em relação aos materiais, as formadoras destacaram a necessidade de existir um trabalho formativo para que todas as instituições de educação infantil atentem para que a questão da diversidade cultural seja contemplada no momento da aquisição de brinquedos, visto que, como mediadores culturais e históricos, os brinquedos veiculam valores e ideias de um determinado contexto histórico, contribuindo com o processo de construção das identidades de meninos e meninas, seja reproduzindo estereótipos ou produzindo processos de singularização (SILVA, 2017a). Assim, faz-se importante que haja nas instituições uma variedade de brinquedos, apresentando expressões das diferenças 
raciais, étnicas, de gênero ou geração, a fim de garantir o reconhecimento, a valorização e o respeito à diversidade. Diversidade que se faz presente também em suas produções culturais.

Sobre a produção das culturas infantis, verificou-se que algumas formadoras abordaram a questão da reprodução da cultura, mas não a sua produção por parte das crianças. Uma das formadoras e algumas professoras mencionaram a possibilidade de as crianças criarem cultura, porém, não ficou claro o modo como elas compreendem esta questão. Todas concordaram acerca da importância de as crianças interagirem com seus pares. Como afirmam Brougère (2008), Corsaro (2011), Prado (1998) e Silva (2017a; 2017b), as crianças constroem cultura por meio das relações estabelecidas nas brincadeiras. Quando brincam e interagem entre seus pares, elas não se limitam a assimilar e a reproduzir a cultura do mundo adulto, mas criam suas próprias experiências de cultura.

P1 chamou a atenção no sentido de que o(a) professor(a) não deve intervir o tempo todo nas brincadeiras, para que os desejos das crianças também se façam presentes. Tal aspecto ficou evidente quando afirmou que "a gente está propondo que vá brincar de uma determinada coisa, mas, ao mesmo tempo, a criança está dizendo: 'O que estou querendo é essa outra coisa.' Então, o que a criança está precisando é outra coisa". Reconhecer e considerar tais necessidades e desejos sugere uma ruptura com o adultocentrismo que ainda marca as relações no âmbito dos espaços educativos. Por meio da transgressão, as crianças demonstram que seus desejos não estão limitados àquilo que os(as) adultos(as) esperam, mas que elas possuem a capacidade de (re)criar e ressignificar a cultura.

A análise dos dados revelou, ainda, a necessidade de um espaço de diálogo entre a equipe de professores(as) e formadoras, o que foi verbalizado pelas próprias professoras, que demonstraram não se sentirem escutadas nos espaços de formação.

\footnotetext{
O que me incomoda é que o acompanhamento das formadoras é mais direcionado para as práticas de alfabetização do que para o brincar livre. (P3) Sem dúvida alguma, concordo. (P2)

A gente não tem espaço para falar sobre isso com as formadoras e acho que elas têm uma rotina também que não dá para elas pararem para escutar. Tipo: "Vem aqui que eu quero te ouvir para saber o que você tem pra falar hoje." Isso nunca aconteceu. Elas já vão nas escolas com um objetivo pontual. (P1)
}

As professoras mencionaram que sentem necessidade de um acompanhamento que não seja voltado às práticas escolarizantes. Segundo as formadoras, não existe o objetivo de que as crianças concluam a educação infantil alfabetizadas, mas reconhecem que as práticas de alfabetização estão presentes na educação infantil e, muitas vezes, os(as) próprios(as) responsáveis pelas crianças cobram a realização de procedimentos que envolvam leitura e 
escrita. Para as professoras, principalmente no que se refere às turmas de crianças de cinco anos, há a necessidade de atrelar o brincar a algum conteúdo, seja este de matemática ou português. Tal fato acontece em decorrência da existência de um caderno de passagem que as crianças precisam fazer e deixar pronto para entregar no primeiro ano do ensino fundamental. Além disso, segundo as docentes, as crianças são submetidas a sondagens, e elas, professoras, são cobradas pela gestão e pela equipe de formadoras acerca da alfabetização das crianças.

Observa-se, portanto, a partir dos dados, a exigência de uma sociedade capitalista que a todo o momento cobra que as crianças sejam cada vez mais cedo submetidas ao tempo do capital, demonstrando o que Marcellino (2003) aponta como um descompasso entre o discurso oficial, que reconhece a importância do lúdico, e as práticas sociais que se desenvolvem no interior das instituições.

\section{Considerações finais}

Brincar é um direito das crianças. Nas brincadeiras descobrem o mundo, comunicam, interagem, recriam, transgridem, resistem e produzem cultura. Compreendendo esse processo, creches e pré-escolas precisam priorizar, em sua proposta curricular, o brincar como um dos eixos do trabalho pedagógico. Porém, observa-se que este direito ainda não é uma realidade em muitas instituições de educação infantil. Pressionados(as) por uma política que busca acelerar os processos de ensino e de aprendizagem, muitos(as) professores(as) terminam por priorizar, em seus cotidianos, atividades voltadas tão somente à alfabetização e ao ensino dos números.

No caso do município em que ocorreu a pesquisa, o brincar limita-se a poucos momentos, observando um predomínio de práticas escolarizantes, sobretudo no que concerne às turmas de crianças de quatro e cinco anos, em detrimento das brincadeiras, o que caracteriza um modelo hegemônico de escola que limita a criatividade e a livre expressão das crianças. No entanto, as professoras demonstraram preocupação frente a esse modelo e apontaram a necessidade de momentos de diálogo com as formadoras, a fim de que possam discutir sobre o brincar.

Vale pontuar que, apesar dos espaços limitados para o brincar, foi possível observar, no estudo exploratório, as transgressões que as crianças fazem frente ao mundo disponibilizado pelos(as) adultos(as), bem como o companheirismo entre elas e a forma como ressignificam materiais, espaços, valores, crenças etc., produzindo, assim, as culturas infantis. Transgressões também foram observadas nos relatos de algumas docentes que, 
atentas às necessidades e aos direitos das crianças, têm transgredido os espaços limitadores do modelo escolarizado e possibilitado, aos meninos e às meninas, momentos para que possam explorar, descobrir, encantar e se reencantar com as coisas do mundo.

Em face dos resultados desta pesquisa, verificou-se a necessidade de construir não só um espaço formativo dialógico, mas também uma pedagogia dialógica na educação infantil. Uma pedagogia que preze pela participação das crianças no cotidiano das instituições, visando garantir que todas tenham assegurado o seu direito ao brincar e à liberdade de se manifestarem, de produzirem cultura e de serem felizes.

\section{Referências}

BARBOSA, Maria Carmem S. Prefácio. In: FARIA, Ana Lúcia Goulart de; MELLO, Suely Amaral. (org.). Territórios da infância: linguagens, tempos e relações para uma pedagogia para as crianças pequenas. Araraquara: Junqueira \& Marin, 2007, p. 5-10.

BARBOSA, Maria Carmen S. Culturas infantis: contribuições e reflexões. Revista Diálogo Educacional, Curitiba, v. 14, n. 43, p. 645-667, set./dez. 2014.

BARDIN, Laurence. Análise de Conteúdo. Lisboa: Edições 70, 2002.

BRASIL. Constituição da República Federativa do Brasil. Promulgada em 1988. Brasília: Senado Federal, 1988.

BRASIL. Lei Federal no 8069/90, de 13 de julho de 1990. Dispõe sobre o Estatuto da Criança e do Adolescente e dá outras providências. 1990.

BRASIL Lei ñ 9.394, de 20 de dez.1996. Estabelece as Diretrizes e Bases da Educação Nacional. Ministério da Educação. 1996.

BRASIL Diretrizes Curriculares Nacionais para a Educação Infantil. Ministério da Educação. Secretaria de Educação Básica. Brasília: MEC/SEB, 2010.

BROUGÈRE, Gilles. Jogo e Educação. Porto Alegre: Artes Médicas, 1998.

BROUGÈRE, Gilles. Brinquedo e Cultura. 7. ed. São Paulo: Cortez, 2008.

CORSARO, William A. Sociologia da Infância. 2. ed. Porto Alegre: Artmed, 2011.

FARIA, Ana Lúcia G. de. O espaço físico como um dos elementos fundamentais para uma pedagogia da educação infantil. In: Faria, Ana Lucia G. de, Palhares, Marina S. (Org.). Educaşão Infantil Pós-LDB: rumos e desafios. São Paulo: Autores Associados, 1999, p. 67-99.

FRANCO, Maria L. P. B. Análise de Conteúdo. 3. ed. Brasília: Liber Livro Editora Ltda, 2008. 
GATTI, Bernardete A. Grupo Focal na Pesquisa em Ciências Sociais e Humanas. Brasília: Liber Livro Editora, 2012.

KISHIMOTO, Tizuko M. Brinquedos e brincadeiras na Educação Infantil. Anais do I Seminário Nacional: Currículo em movimento - Perspectivas Atuais. Belo Horizonte, novembro de 2010. Disponível em: $<$ https://moodle.ufsc.br/mod/resource/view.php?id=497687 >. Acesso em: 25 ago. 2019.

KISHIMOTO, Tizuko M. Jogo, brinquedo, brincadeira e a educaşão. 14. ed. São Paulo: Cortez, 2011.

KISHIMOTO, Tizuko M. Jogos Infantis: O jogo, a criança e a educação. 18. ed. São Paulo: Vozes, 2014.

KISHIMOTO, Tizuko M. O jogo e a educação infantil. São Paulo: Cengage Learning, 2015.

KISHIMOTO, Tizuko M. Escolarização e brincadeira na educação infantil. Labrinjo: Laboratório de Brinquedos e Jogos, s/d. Disponível em: <http://www.labrinjo.ufc.br/phocadownload/artigo_005.pdf>. Acesso em: 25 maio 2019.

MALAGUZZI, Loris. História, ideias e filosofia básica. In: EDWARDS, Carolyn; GANDINI, Lella; FORMAN, George. As cem linguagens da criança: a abordagem italiana de Reggio Emília na educação da primeira infância. Porto Alegre: Artes Médicas, 1999, p. 59104.

MARCELLINO, Nelson C. Pedagogia da Animação. 5. ed. São Paulo: Papirus, 2003.

PRADO, Patrícia D. Educaşão e Cultura Infantil em Creche: um estudo sobre as brincadeiras de crianças pequenininhas em um CEMEI de Campinas/SP. 1998. 201 p. Dissertação (Mestrado em Educação) - Faculdade de Educação da Universidade Estadual de Campinas, Campinas, 1998.

SILVA, Marta R. P. da. "Essa ciranda não é minha só, é de todos nós": o brincar e as culturas infantis. Guia de Estudos Pedagogia EAD. São Bernardo do Campo: Metodista, $2017 \mathrm{a}$.

SILVA, Marta R. P. da. Por uma educação infantil emancipatória: a vez e a voz das crianças e de suas educadoras. Cadernos de Educação. Pelotas: UFPel, n. 58, p. 83-100, 2017b. Disponível em: $<$ https://periodicos.ufpel.edu.br/ojs2/index.php/caduc/article/view/12370>. Acesso em 20 ago. 2019.

WAJSKOP, Gisela. Brincar na pré-escola. São Paulo: Cortez, 1995.

WAJSKOP, Gisela. Brincar na educação infantil: uma história que se repete. 9. ed. São Paulo: Cortez, 2012. 
Recebido em: 20 mar. 2019 / Aprovado em: 25 jun. 2019

\section{$\underline{\text { Cite como }}$}

SILVA, Marta Regina Paulo da; FRANCESCHINI Luciene. Apenas brincando? Brinquedos e brincadeiras na educação infantil: o que dizem as educadoras?.Dialogia, São Paulo, n. 33, p. 218-232, set./dez. 2019. Disponível em: https://doi.org/10.5585/Dialogia.n33.15412. 